\title{
ACUTE MONOCYTIC LEUKAEMIA WITH RESPONSE TO METHOTREXATE
}

\author{
BY \\ VICTOR DUBOWITZ \\ From the Department of Child Health, University of Sheffield
}

(RECEIVED FOR PUBLICATION SEPTEMBER 5, 1963)

Acute monocytic leukaemia in childhood is much less common than the acute lymphoblastic and acute myeloblastic forms. It is also much more resistant to the conventional forms of therapy.

Among the 100 cases of acute leukaemia in childhood reviewed by Lightwood, Barrie and Butler (1960), five were diagnosed as acute monoblastic: two of these received drug therapy, cortisone alone in one, and cortisone, aminopterin, mercaptopurine and nitrogen mustard in the other, and neither went into remission.

In a study of 50 consecutive cases of acute leukaemia in childhood, Thompson and Walker (1962) found only one case of acute monocytic leukaemia. The result of therapy is not mentioned separately but included with 11 cases of myeloid leukaemia. Six of this group were treated but only one showed some response.

Mahfoux and Amin (1961) reported on the beneficial effect of methotrexate in four cases of acute leukaemia. Two were said to be of acute monocytic type, but no clinical or haematological details were included.

The patient to be described had typical acute monocytic leukaemia of the Naegeli type. After failing to respond to prednisolone, mercaptopurine and repeated blood transfusions, she went into clinical and haematological remission on methotrexate (Fig. 1).

\section{Case History}

An 8-year-old girl was admitted to the Children's Hospital on January 22, 1963, with a six-week history of progressive lethargy, recurrent sore throat, swelling and bleeding of the gums, and pallor. On examination there was significant pallor of the skin and mucous membranes, gross hypertrophy of the gums (Fig. 2), and generalized slight lymphadenopathy. The liver was enlarged to one finger's breadth below the costal margin and the tip of the spleen was just palpable without inspiration.

A provisional diagnosis of acute leukaemia was made, possibly monocytic in view of the gum hypertrophy.
Haematological Investigations. Haemoglobin $5.6 \mathrm{~g} . /$ $100 \mathrm{ml}$; white cell count 82,000 with monocytes $55 \%$, lymphocytes $16 \%$, polymorphs $15 \%$, myelocytes $7 \%$, metamyelocytes $5 \%$ (Fig. 3). Platelets 60,000.

The bone marrow contained $37 \%$ monocytes and $18 \%$ blast cells (Fig. 4). There was a significant reduction in erythroid elements $(12 \%)$.

A diagnosis of acute monocytic leukaemia of the Naegeli type was made.

Course and Treatment. Therapy was commenced on the day of admission with prednisolone $15 \mathrm{mg}$. every six hours, and mercaptopurine $25 \mathrm{mg}$. twice daily. Her weight was $52 \mathrm{lb}$. $(23.6 \mathrm{~kg}$.). There was no sign of immediate response and her clinical condition deteriorated. By January 26 the haemoglobin was unchanged, but the white cells had risen to 150,000 per c.mm. with $60 \%$ monocytes and 3\% blast cells (Fig. 1).

A transfusion of one pint of packed cells on January 27 raised the haemoglobin to $11.4 \mathrm{~g}$. per $100 \mathrm{ml}$. The prednisolone dosage was reduced to $10 \mathrm{mg}$. every six hours, the mercaptopurine being continued as before.

By February 7 the haemoglobin had fallen to $5 \cdot 2 \mathrm{~g}$.l $100 \mathrm{ml}$. and the white cell count had risen to $190,000 /$ c.mm., with $88 \%$ monocytes. After a further transfusion of one pint of packed cells on February 8, the haemoglobin rose to $10 \cdot 2 \mathrm{~g} . / 100 \mathrm{ml}$., but by February 13 it had fallen to $7 \cdot 8 \mathrm{~g} . / 100 \mathrm{ml}$.

Clinically there was no sign of improvement and she looked ill and was lethargic, listless and irritable. She developed extensive purpura over both legs and a small subconjunctival haemorrhage. Her face was Cushingoid from the steroid therapy, indicating adequate absorption.

Methotrexate, $4 \mathrm{mg}$. daily, was added on February 14. Two days later her haemoglobin was $5.9 \mathrm{~g} . / 100 \mathrm{ml}$. and the white cell count 146,000 with $74 \%$ monocytes and $2 \%$ blast cells. A further transfusion was given on February 17. Although her haemoglobin dropped from $8.7 \mathrm{~g}$. on February 18 to $5.6 \mathrm{~g}$. on February 25 , there was a noticeable clinical improvement during this time. The white cell count fell sharply to 53,000 on February 18 and to 23,000 on February 25, with a drop in monocytes to $28 \%$. The gum hypertrophy which was unchanged on February 14 had completely subsided by February 26.

When the white cell count dropped below 10,000 


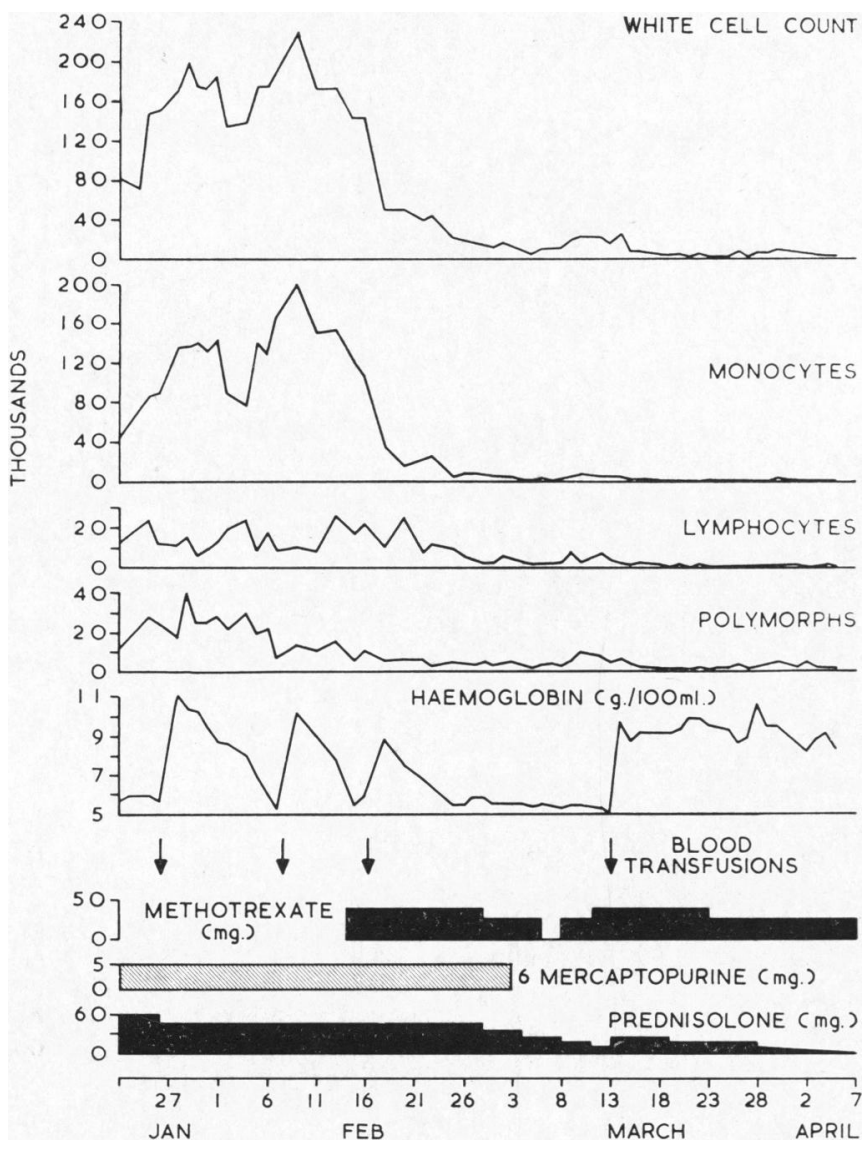

Fig. 1.-Haematological data and therapy.

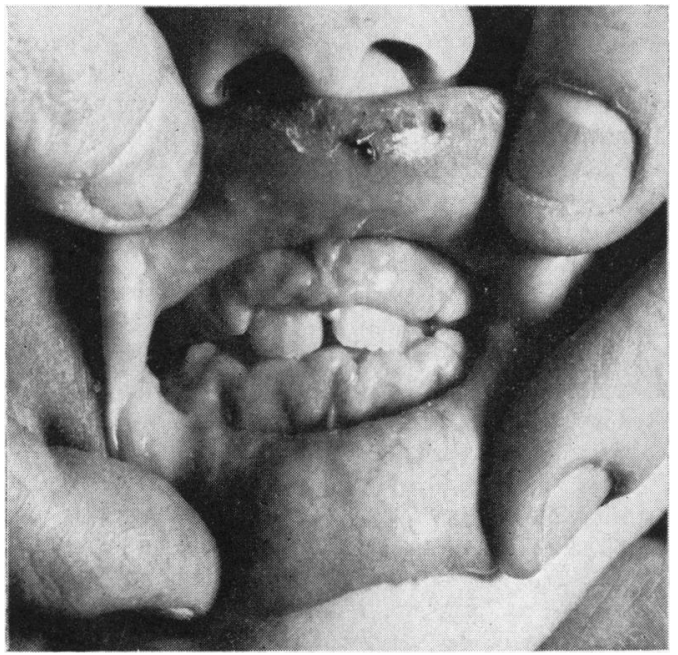

Fig. 2.-Hypertrophy of the gums. per c.mm. the methotrexate was intermittently stopped or adjusted according to the cell count. On February 28, for the first time, there were 8 nucleated red cells per 200 white cells.

The haemoglobin level remained steady at between 5 and $5.5 \mathrm{~g} . / 100 \mathrm{ml}$. and her clinical condition continued to improve. She was given another transfusion on March 13, after which the haemoglobin rose to $9.9 \mathrm{~g}$.

Mercaptopurine was stopped on March 6. Prednisolone was gradually tapered off, under cover of a weekly injection of 40 units of corticotrophin and was discontinued on April 5.

She had an acute respiratory infection from March 12-16, which responded well to penicillin in addition to the maintenance dose of tetracycline she was already receiving. The prednisolone was temporarily increased during this period.

She was discharged on April 5 on methotrexate $2.5 \mathrm{mg}$. daily. Her haemoglobin was $8.4 \mathrm{~g} . / 100 \mathrm{ml}$., white cell count 4,000 with polymorphs $60 \%$, lymphocytes $31 \%$, monocytes $9 \%$ and 3 nucleated red cells per 100 white cells. 


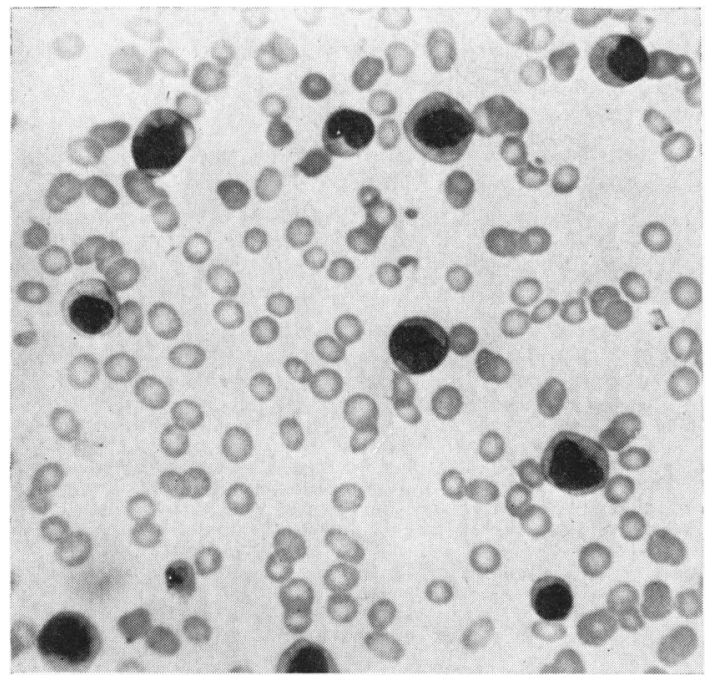

Fig. 3.-Peripheral blood. Numerous monocytic cells. (Leishman stain $\times 366$.)

At out-patient follow-up she continued well and was able to return to school. Her haemoglobin varied from 8 to $10 \mathrm{~g} . / 100 \mathrm{ml}$., and white cell count from 2,500 to 4,500 .

On June 20, after a week's holiday by the sea, she was not so well. Her complexion was sallow, her haemoglobin had dropped to $7 \mathrm{~g} . / 100 \mathrm{ml}$. and the white cells to 2,200 with lymphocytes $52 \%$, polymorphs $34 \%$, monocytes $11 \%$ and blast cells $3 \%$. There were 4 nucleated red cells per 100 white cells. The methotrexate was increased to $2.5 \mathrm{mg}$. twice daily.

By June 24 she was worse. Haemoglobin had dropped to $5.8 \mathrm{~g} . / 100 \mathrm{ml}$., white cell count was 3,000 with $3 \%$ blast cells. She had numerous ulcers in her mouth. By June 27 her clinical condition had deteriorated considerably, although her blood picture was unchanged. She also developed frequent loose stools.

A bone marrow biopsy showed a hypercellular marrow with a preponderance of blast cells $(51 \%)$. The picture was more primitive than at the time of the first admission.

No pathogens were cultured from the stools. The diarrhoea and oral ulcers were thought to be secondary to the methotrexate. However, in view of the florid relapse in the bone marrow picture, and the presence of nucleated red cells in the peripheral blood, it was thought that the only hope lay in increasing rather than stopping the methotrexate, and the dose was raised to $2.5 \mathrm{mg}$. every six hours.

A transfusion of packed cells raised the haemoglobin to $9.0 \mathrm{~g} . / 100 \mathrm{ml}$. Although the white cell count remained steady, her clinical condition steadily deteriorated. In spite of the reasonable haemoglobin level she was listless and lethargic as well as irritable and uncooperative, a state frequently seen in children with relapse of leukaemia.

There was no lymphadenopathy, hepatic or splenic enlargement, or gum hypertrophy. Despite intra-

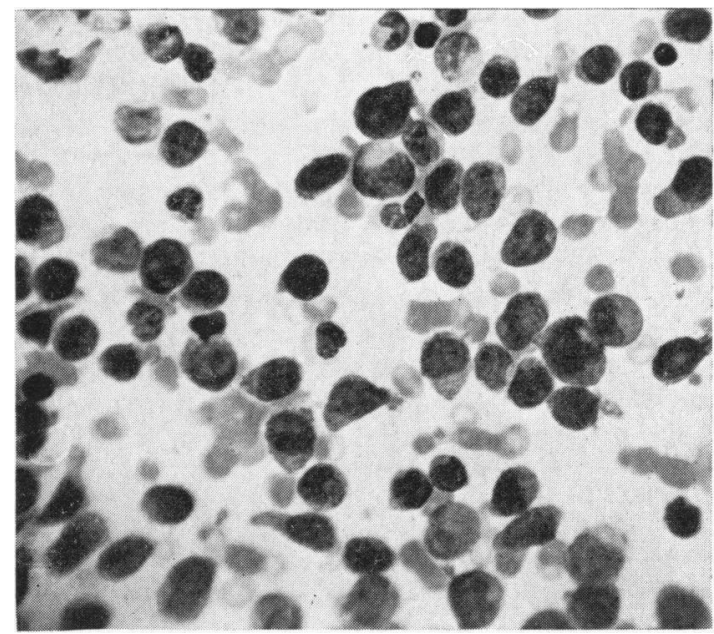

FIG. 4. Bone marrow: preponderance of monocytic cells. $($ Leishman stain $\times 366$.)

venous methotrexate she declined rapidly and died on July 3.

\section{Discussion}

The clinical and haematological findings in this patient are in keeping with a diagnosis of acute monocytic leukaemia. Gum hypertrophy is more common in acute monocytic leukaemia than in the other forms. Boggs, Wintrobe and Cartwright (1962) observed gum hypertrophy in $34 \%$ of their patients with monocytic leukaemia, in contrast to $8 \%$ of those with myeloblastic and $2 \%$ of those with lymphoblastic leukaemia. Watkins and Hall (1940) suggested that gum hypertrophy was limited to the Naegeli type of acute monocytic leukaemia.

The presence of myelocytes and metamyelocytes in the peripheral blood is consistent with the Naegeli type, in contrast to the Schilling type of acute monocytic leukaemia where the predominant cell resembles a histiocyte.

Boggs et al. (1962) define a remission as the 'return of the blood and physical abnormalities to normal in an asymptomatic patient'. They do not consider it necessary to document a bone marrow remission as an additional criterion. By these criteria methotrexate produced a remission in our patient. The abnormal clinical signs resolved and the patient was asymptomatic. The blood picture was normal apart from a low haemoglobin and platelet level. However, these showed no evidence of dropping from their steady levels.

Acute monocytic leukaemia may have a rapidly downhill course. One patient of Lightwood et al. (1960), with only a week's history of symptoms, 
died within two days of admission. On the other hand, there are a number of cases on record who survived up to three or four months on supportive therapy. However, they did not go into clinical or haematological remission.

In view of the rapid remission produced in this patient by methotrexate, this drug may be the therapy of choice in acute monocytic leukaemia and should be administered in the first instance. There are no cases on record of remission produced in acute monocytic leukaemia in childhood by steroid or mercaptopurine therapy, so that there is no justification for an initial trial of the latter drugs.

\section{Summary}

Methotrexate produced a clinical and haematological remission of acute monocytic leukaemia in an 8-year-old girl. The remission lasted four months and the total survival from the onset of symptoms was seven months.

I wish to thank Dr. John Emery and the Pathology Department, Sheffield Children's Hospital, for the blood and marrow counts, Dr. E. K. Blackburn and Dr. M. C. G. Israëls for their helpful comments, Mr. A. S. Foster for the graph, and Mr. A. K. Tunstill for the photography.

\section{REFERENCFS}

Boggs, D. R., Wintrobe, M. M. and Cartwright, G. F. (1962). The acute leukemias. Analysis of 322 cases and review of the literature. Medicine (Baltimore), 41, 163.

Lightwood, R., Barrie, H. and Butler, N. (1960). Observations on 100 cases of leukaemia in childhood. Brit. med. J., 1, 747.

Mahfoux, M. M and Amin, N (1961). Methotrexate in acute leukaemias of childhood with special reference to monocytic leukaemias of childhood with special referenc.

Thompson, R. B. and Walker, W. (1962). Study of 50 cases of acute leukaemia in childhood. Brit. med. J., 1,1165 .

Watkins, C. H. and Hall, B. E. (1940). Monocytic leukemia of the Naegeli and Schilling types. Amer. J. clin. Path., 10, 387. 